The New Front-End Electronics For the ATLAS Tile Calorimeter Phase 2 Upgrade

\author{
Gary Drake \\ Argonne National Laboratory, USA
}

On behalf of the ATLAS TileCal System

IEEE Nuclear Science Symposium

San Diego, CA USA

Nov. 3, 2015 


\section{The LHC at CERN}

- The Large Hadron Collider at CERN in Geneva, Switzerland

- 27 km diameter tunnel, 100 m deep underground Switzerland \& France

- Accelerator capable of colliding proton-proton beams at $14 \mathrm{TeV}$ at 4 locations

- $\quad$ 1 billion collisions per second

- 4 primary experiments along the ring
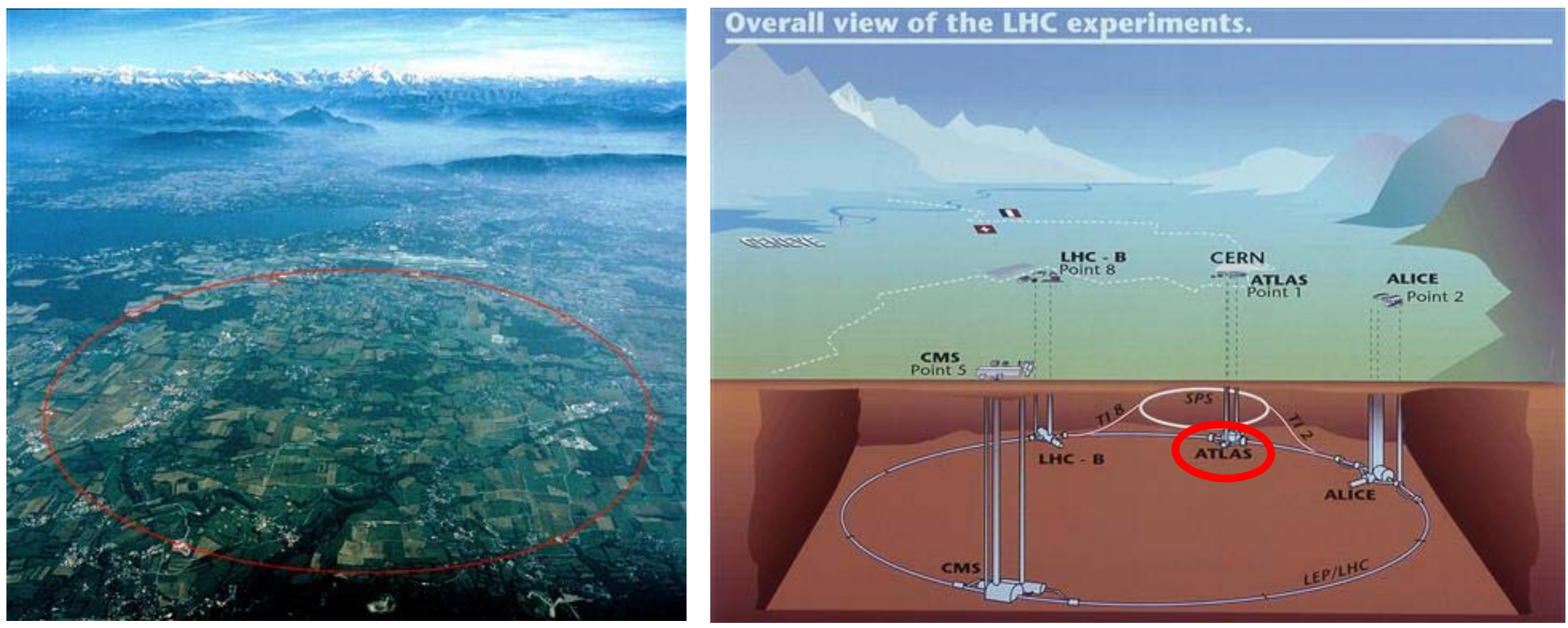


\section{The ATLAS Experiment}

\section{- The Detector for ATLAS}

- Designed to measure particles created from proton-proton collisions at $\sqrt{s}=14 \mathrm{TeV}$ energies

- Composed of 6 different detector subsystems wrapped concentrically around the collision point

- Measure trajectory, momentum, and energy of particles, allowing them to be individually
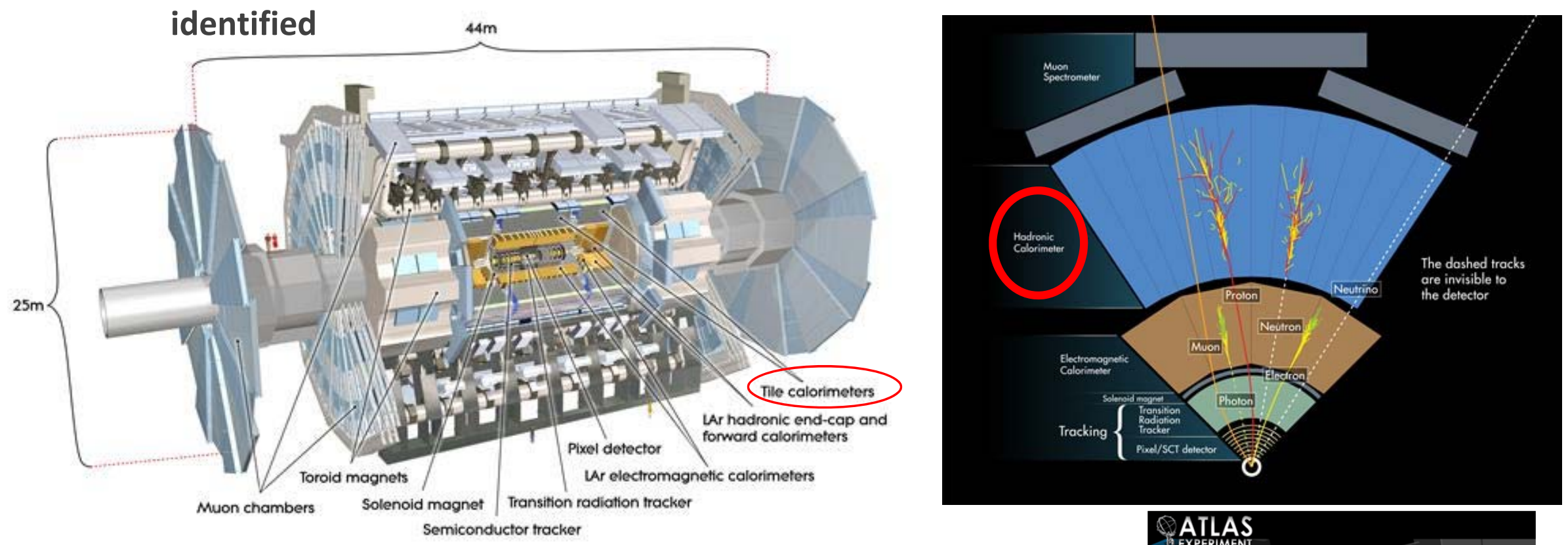

- Diameter $25 \mathrm{~m}$-- Length : $46 \mathrm{~m}$

- Barrel toroid length $26 \mathrm{~m}$

- Overall weight 7000 tonnes

- $\quad 100$ million electronic channels

- $\quad \sim 3000 \mathrm{~km}$ of cables

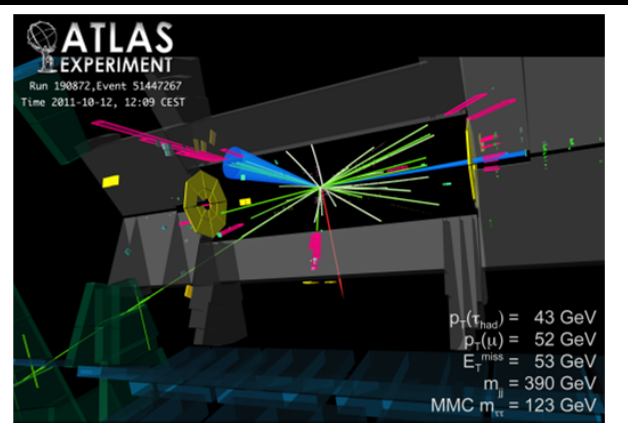

Electronics for ATLAS TileCal Phase 2 Upgrade - G. Drake - 2015 IEEE NSS, San Diego, CA - Nov. 3, 2015 


\section{The ATLAS Hadronic Calorimeter (TileCal)}

- The Tile Calorimeter - Steel \& Scintillating Tiles w/WLS Fibers; PMT Readout
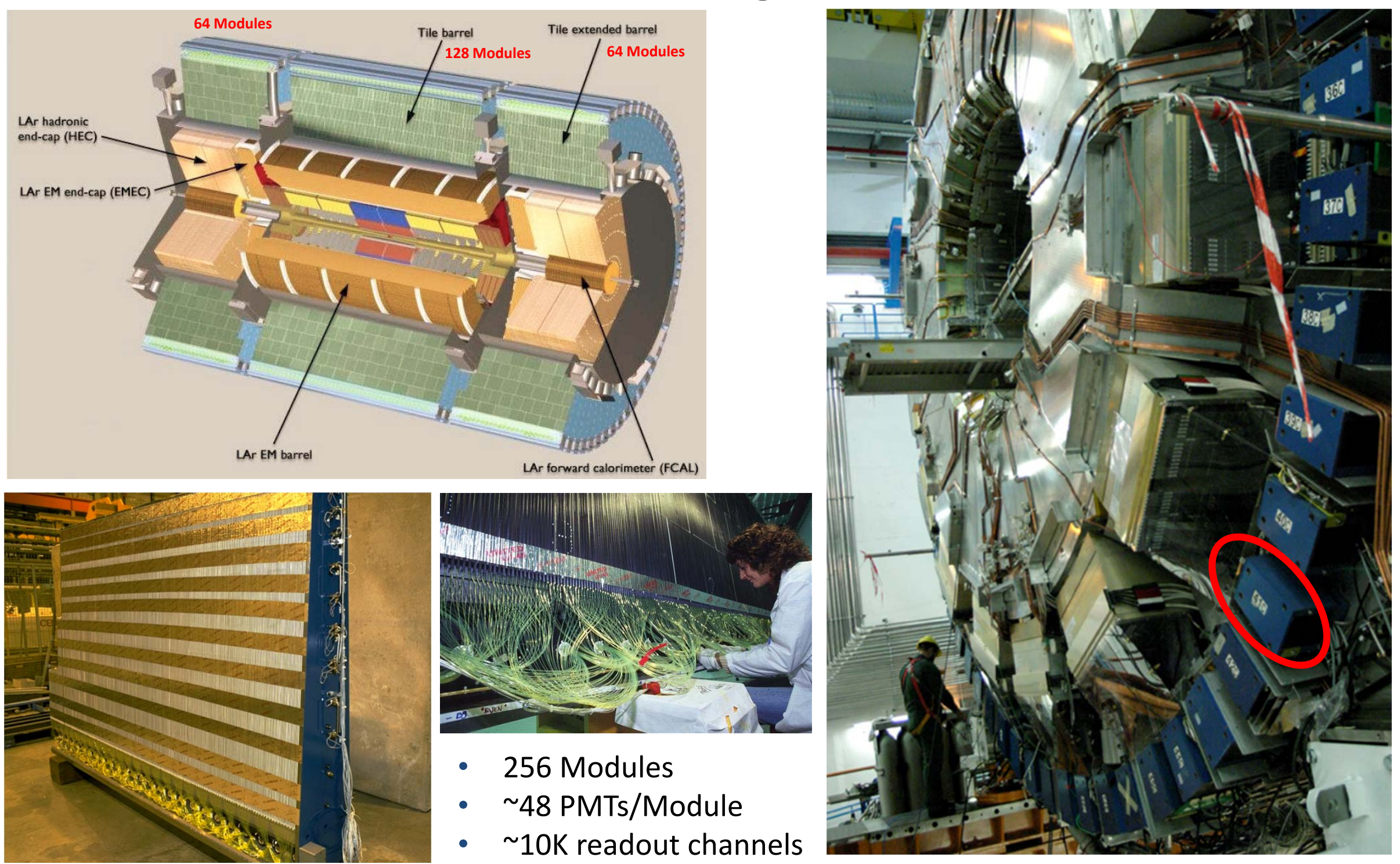

Electronics for ATLAS TileCal Phase 2 Upgrade - G. Drake - 2015 IEEE NSS, San Diego, CA - Nov. 3, 2015

- 256 Modules

- 48 PMTs/Module

- $\quad$ 10K readout channels 


\section{Current Electronics Architecture}

- Each module hosts self-contained instrumentation $\rightarrow$ "Super Drawer"

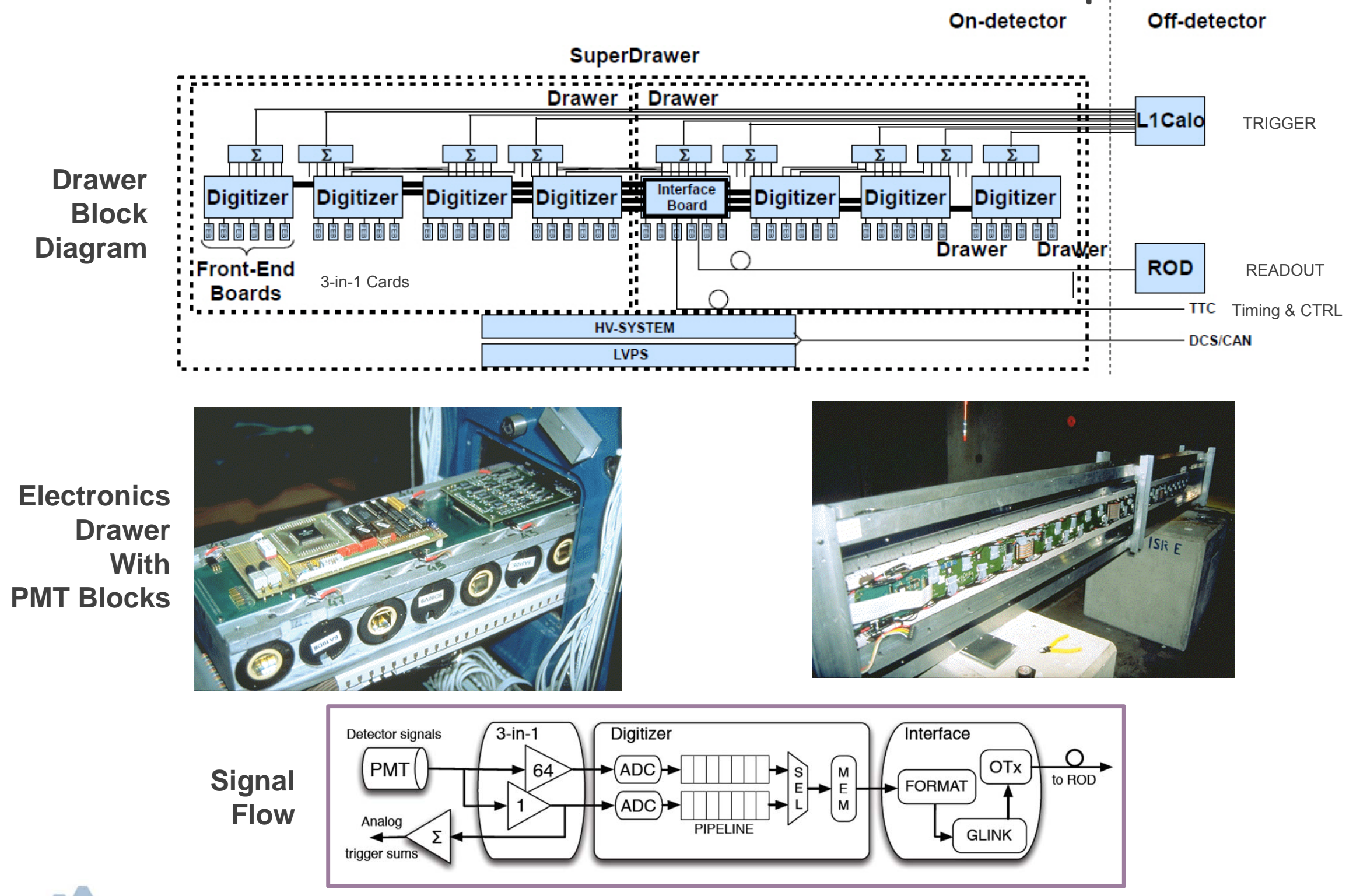




\section{Drivers for the TileCal Phase 2 Upgrade}

- By 2022, current electronics will have reached end-of-life

- Make use of new, modern parts

- Need for higher radiation tolerance for the future

- Planning on X10 increase in radiation tolerance

- Desire to send ALL data off of detector for every beam crossing

- Digitize at Bunch Crossing Rate

- Part of LAr/L1Calo plans as well

- Desire to implement a digital trigger

- Part of LAr/L1Calo plans as well

- Desire to implement redundant power supplies in the front-end

- Source of problems in current system

- Desire to reduce single point failures in the front-ends

- Data drivers, optical links, dual-sided PMT read-out

- Desire to improve accessibility of electronics in the drawers

- Desire to fix other system and implementation issues in the drawers

- We have learned a lot about the current system...

$\Rightarrow 4$ Themes: Full Data Readout; Digital Trigger; Radiation Tolerance; High Reliability

Electronics for ATLAS TileCal Phase 2 Upgrade - G. Drake - 2015 IEEE NSS, San Diego, CA - Nov. 3, 2015 


\section{Upgrade Electronics Architecture}

\section{- Each Module contains 4 "Mini Drawers"}

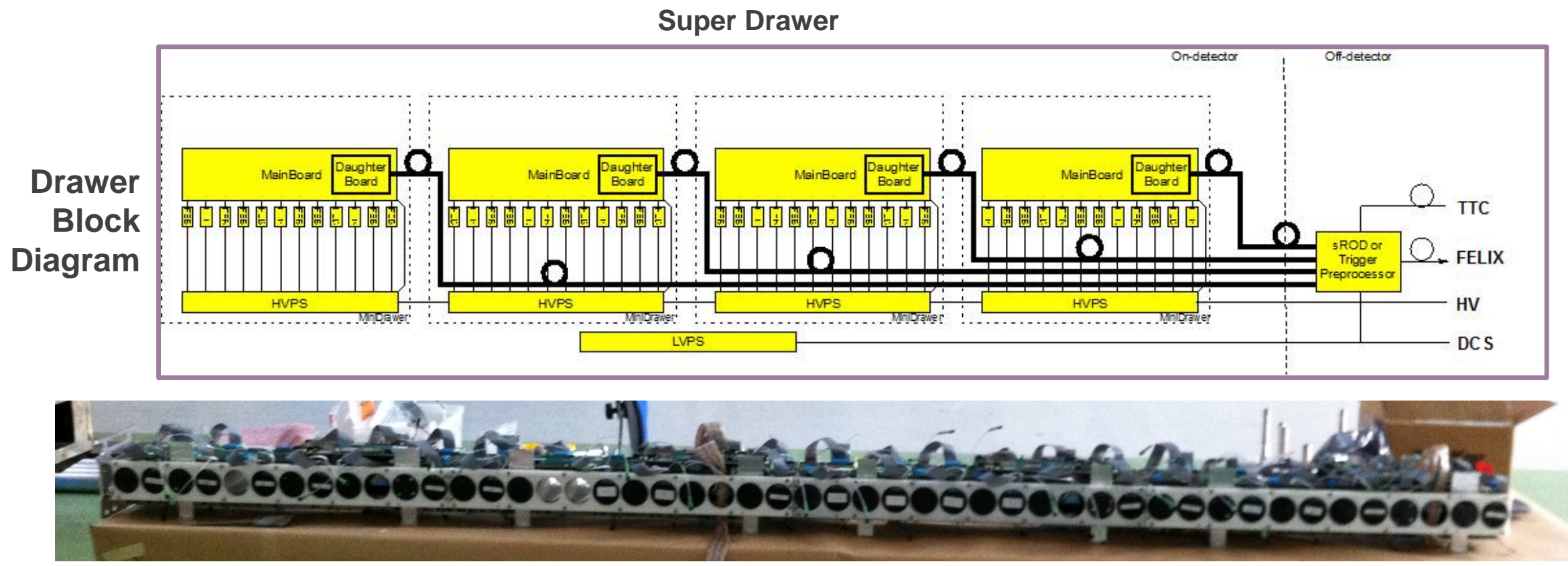

4 Mini Drawers With PMT Blocks

$\Rightarrow$ "Drop-in" replacement for current instrumentation

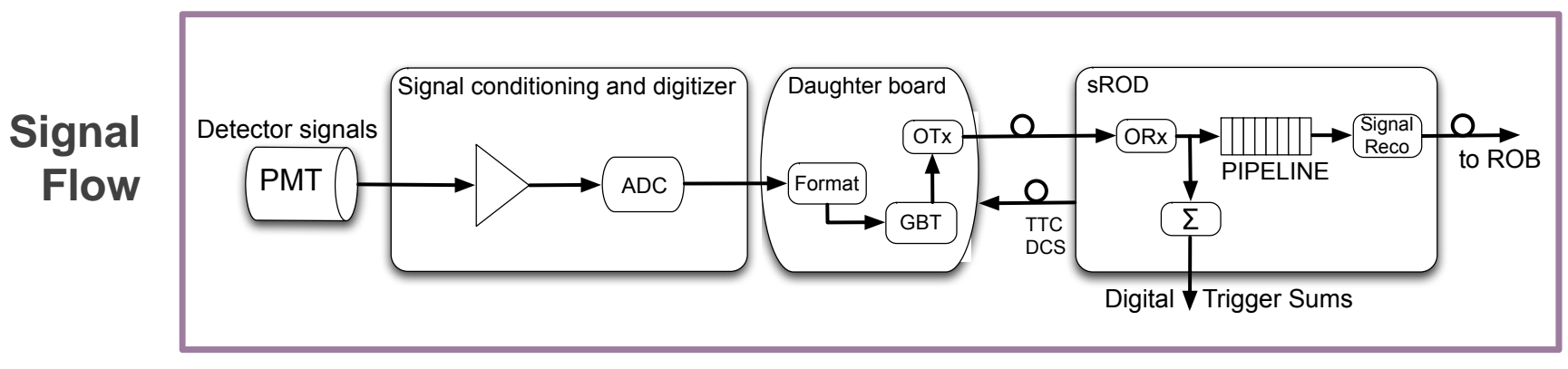

\begin{tabular}{|l|c|c|}
\hline \multicolumn{1}{|c|}{ Parameter } & Present & Upgrade \\
\hline Total BW & $\sim 165 \mathrm{Gbps}$ & $\sim 80 \mathrm{Tbps}$ \\
\hline \# Links & 256 & 8192 \\
\hline Data Rate / Link & $640 \mathrm{Mbps}$ & $9.6 \mathrm{Gbps}$ \\
\hline \# Links / Drawer & $1(+1)$ & $4 \times 4(+4 \times 4)$ \\
\hline Input BW/ROD & $5 \mathrm{Gbps}$ & $625 \mathrm{Gpbs}$ \\
\hline Out BW/ROD DAQ & $2.56 \mathrm{Gbps}$ & $\sim 5 \mathrm{Gbps}$ \\
\hline Out BW/ROD & Analog FE & $<80 \mathrm{Gbps}$ \\
\hline
\end{tabular}

Electronics for ATLAS TileCal Phase 2 Upgrade - G. Drake - 2015 IEEE NSS, San Diego, CA - Nov. 3, 2015 


\section{Upgrade Electronics Architecture}

- Our plan: Staged Approach $\rightarrow$ "Demonstrator" $\underset{\substack{\text { on-detector } \\ \text { off-detector }}}{\operatorname{Interface} \text { toxing System }}$

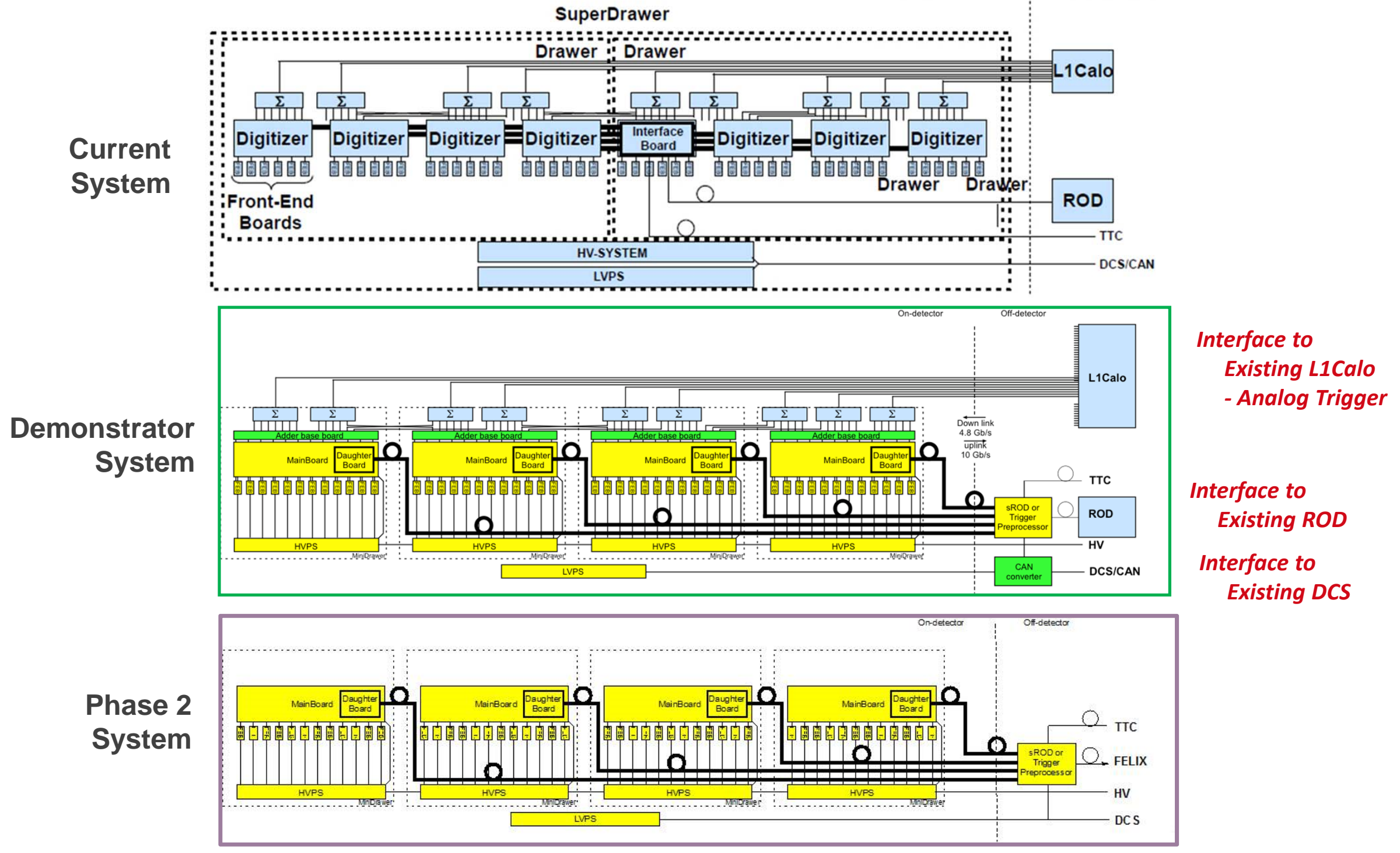

Electronics for ATLAS TileCal Phase 2 Upgrade - G. Drake - 2015 IEEE NSS, San Diego, CA - Nov. 3, 2015 


\section{Goals of the Demonstrator Program}

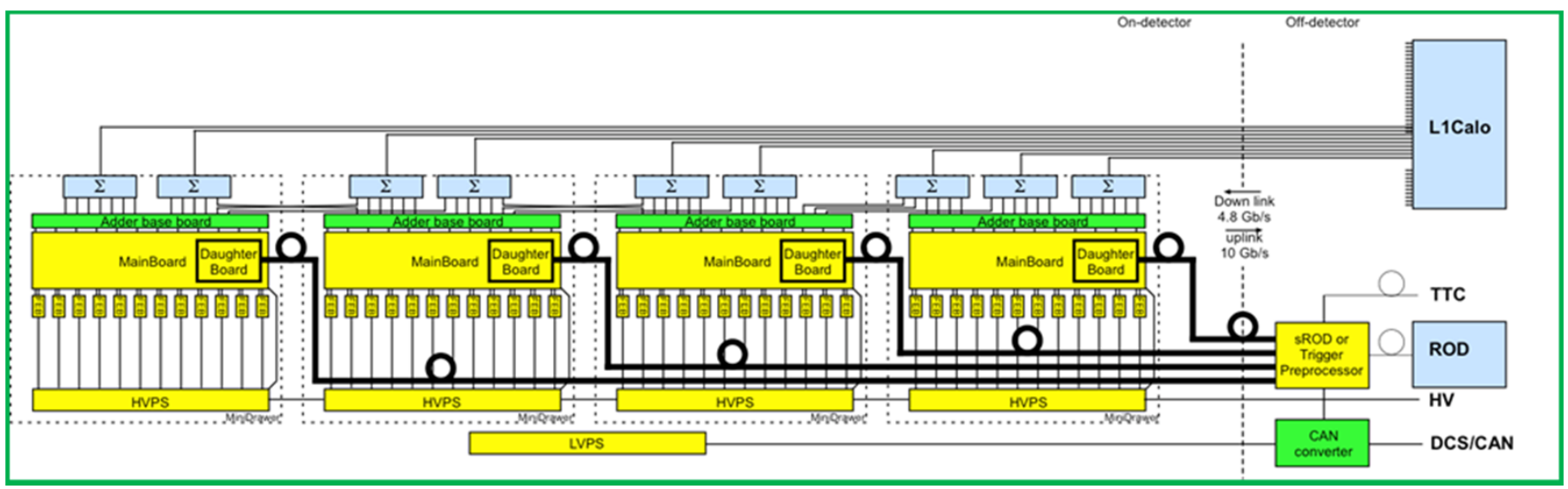

- Allows study and development of new electronics using existing infrastructure, including:

- $\quad$ Digital trigger processing

- New Trigger Pre-Processor

- Optical links \& serial protocols

- Redundant power system, \& data acquisition

- Calibrations, slow controls, diagnostics

- Allows the direct comparison with the old system performance

- Allows the direct comparison between the different technologies

$\Rightarrow$ A TileCal Goal: To install one or more Demonstrator Modules onto the detector before the Phase 2 Upgrade

$\Rightarrow$ Will help identify bugs and problem areas before production in $\sim 2020$

Electronics for ATLAS TileCal Phase 2 Upgrade - G. Drake - 2015 IEEE NSS, San Diego, CA - Nov. 3, 2015 


\section{Mini Drawers}

- Super Drawers will be composed of 4 mini-drawers, each containing:

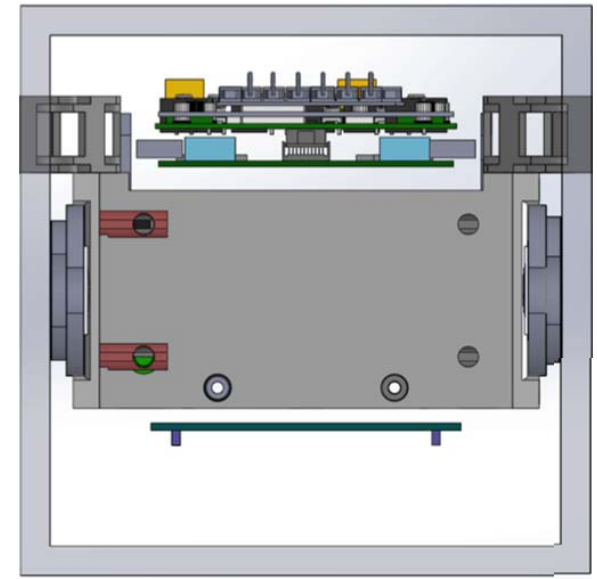

- 12 PMT blocks with active dividers

- 12 Front-End Boards, 6 per side

- 1 Main Board

- 1 Daughter Board

- $1 \mathrm{HV}$ regulation board

- 1 adder base board +3 adder cards (for the hybrid Demonstrator)

Cross section of a mini-drawer

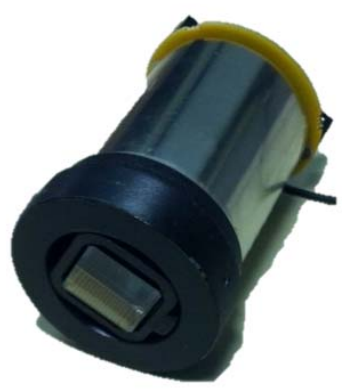

Required assembly of 45 PMT blocks with new active dividers

Rigid mechanical links for hybrid demonstrator)

Cable carrier (1 adders, 1 digital)

Cooling pipe links

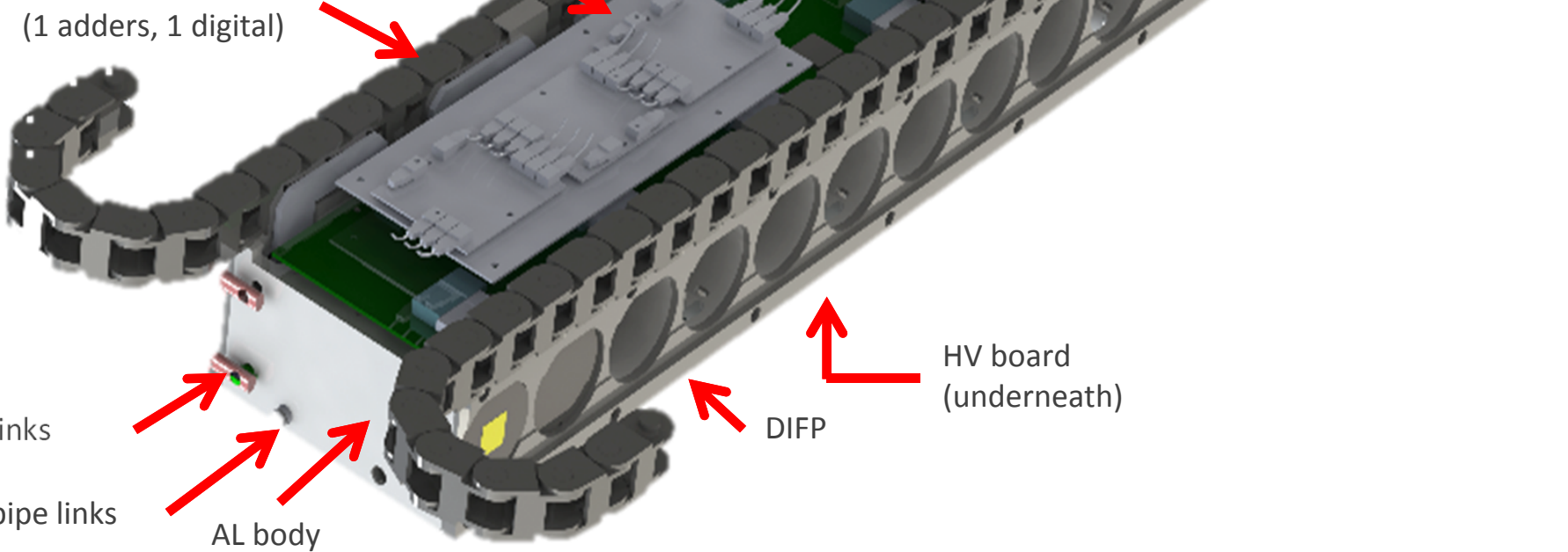




\section{Mini Drawers}

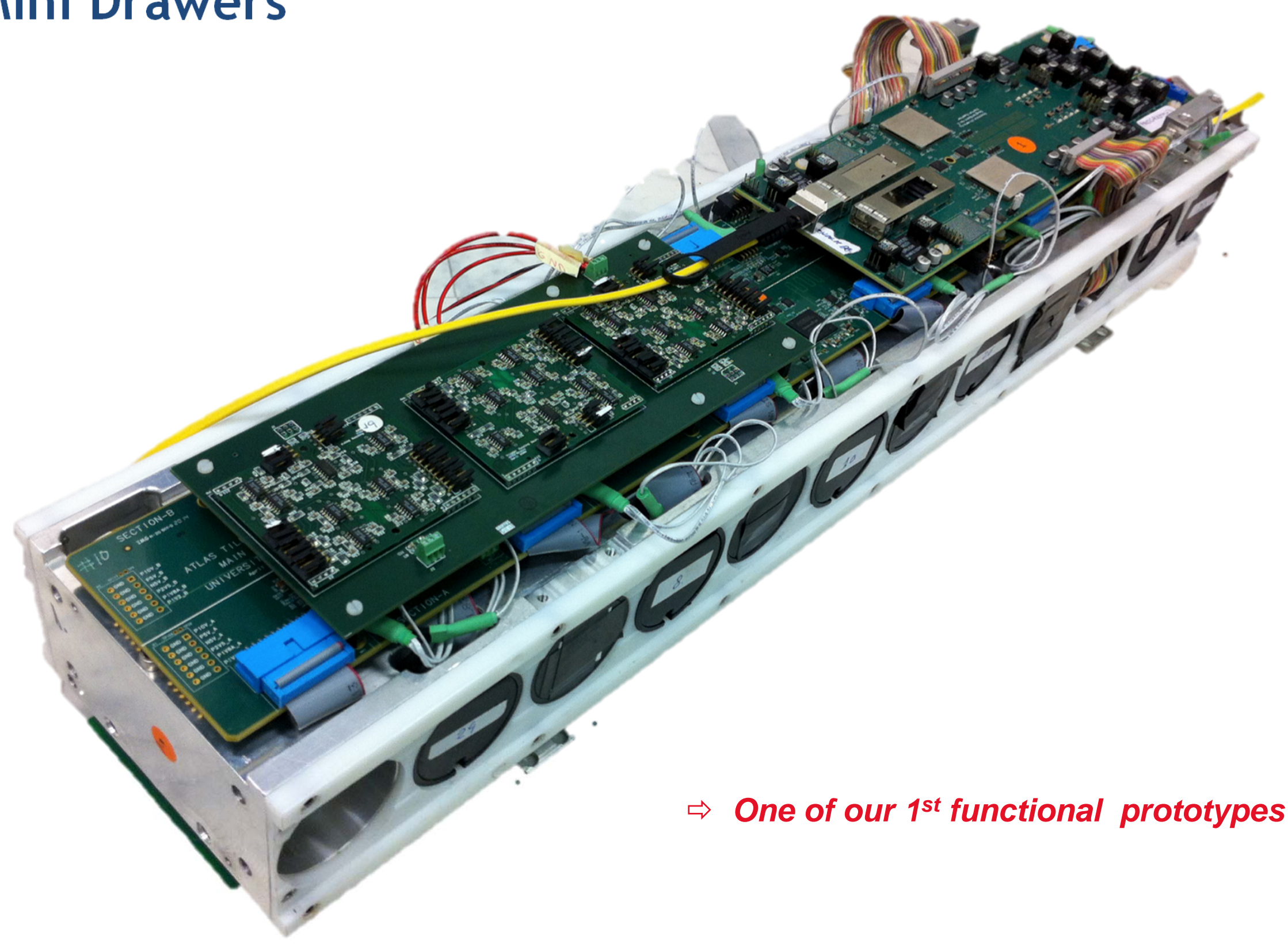

Electronics for ATLAS TileCal Phase 2 Upgrade - G. Drake - 2015 IEEE NSS, San Diego, CA - Nov. 3, 2015 


\section{Mini Drawers}

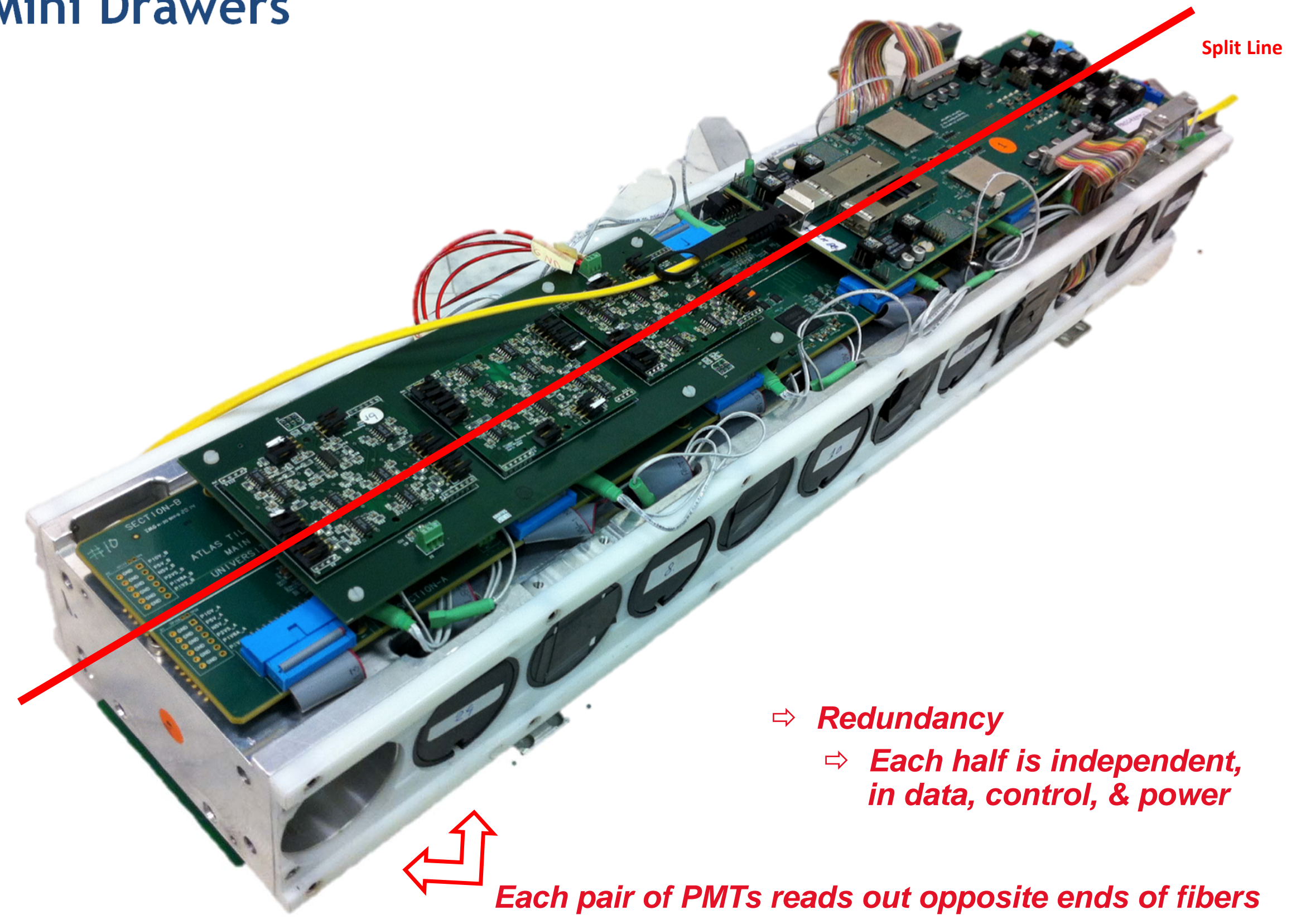

Electronics for ATLAS TileCal Phase 2 Upgrade - G. Drake - 2015 IEEE NSS, San Diego, CA - Nov. 3, 2015 


\section{Front End Boards}

- Functionality

- Resides inside PMT Blocks

- Short signal path

- Excellent shielding

- Baseline FEB design: 3-in-1

- Improved version of the present design -
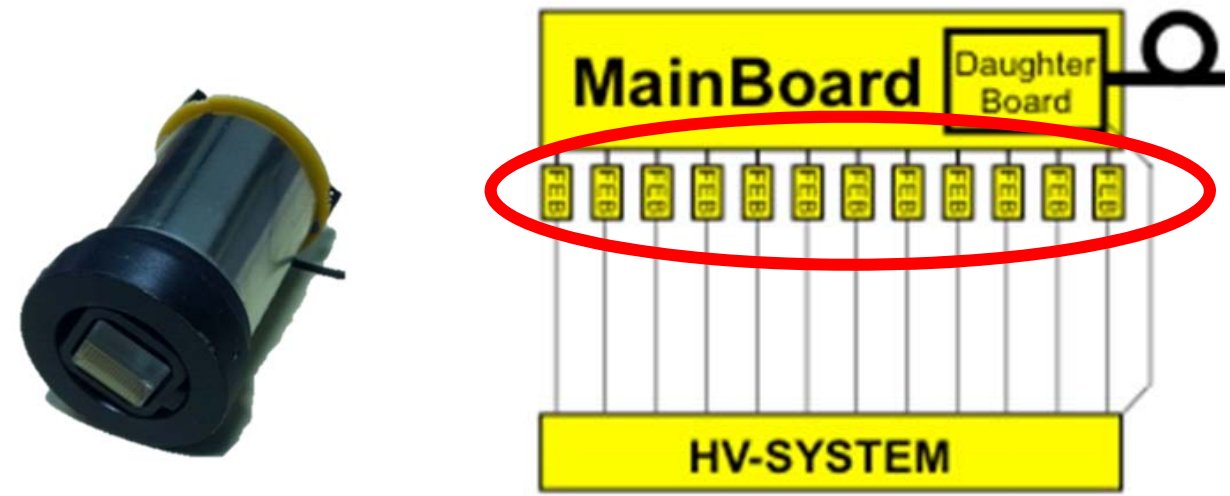
made with discrete components

- Improved linearity

- Improved radiation tolerance

- +/- $5 \mathrm{~V}$ power

- Contains 7-pole passive shaper

- 3 main functions:

- High and low gain analog outputs

- Charge injection calibration

- Integrator to read out Cs calibration data

- Sends analog signals out to Main Board for digitization

- Has analog trigger output, for use in the Hybrid Demonstrator

$\Rightarrow 2$ Alternative Options being Considered:

$\Rightarrow$ QIE ASIC

$\Rightarrow$ FATALIC ASIC

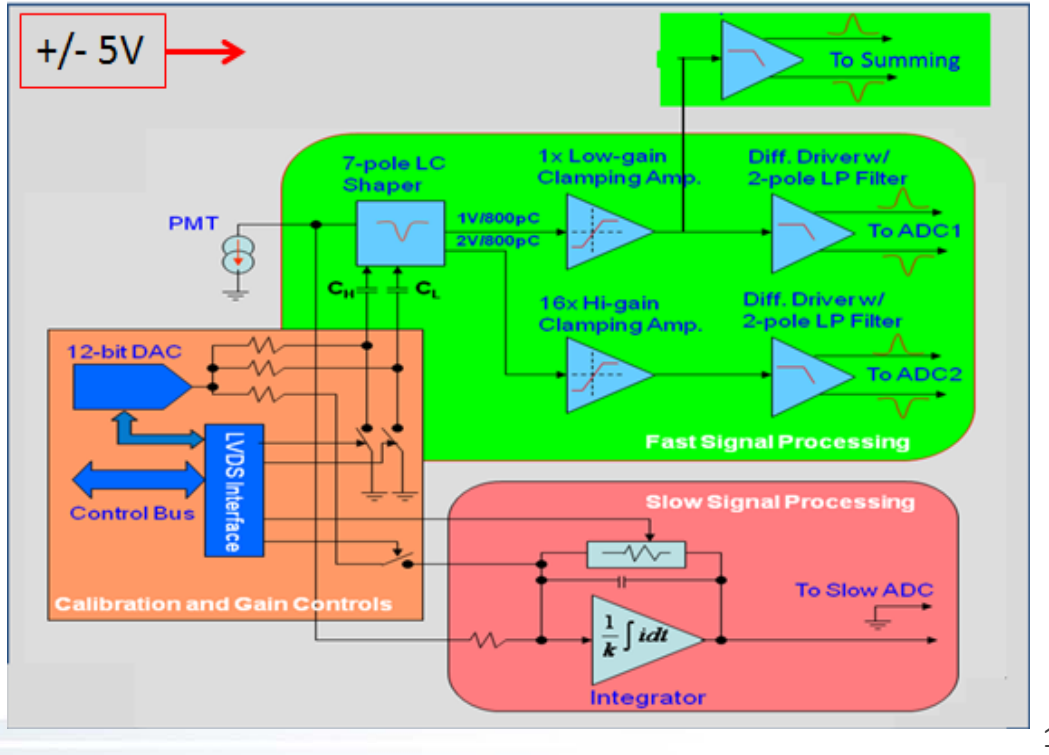




\section{Main Board}

- Functionality

- Interface between FEBs and Daughter Board

- Board is split so that 2 halves independent in data \& power for redundancy

- Each cell will be read-out by two PMTs, one on each side of the mainboard

- Baseline design: Support 3-in-1 FEB

- Contains discrete, commercial ADCs for digitizing FEB analog output signals

- Samples are transferred serially to the daughterboard at $600 \mathrm{MHz}$

- Contains FPGA used for slow control and calibration

- Commands are sent in parallel to 2 control FPGAs on each side

- Contains Point-of-Load (POL) Regulators for regulating $+10 \mathrm{~V}$ to voltages needed by FEB \& MB circuits

$\Rightarrow 2$ Alternative designs for each FE option

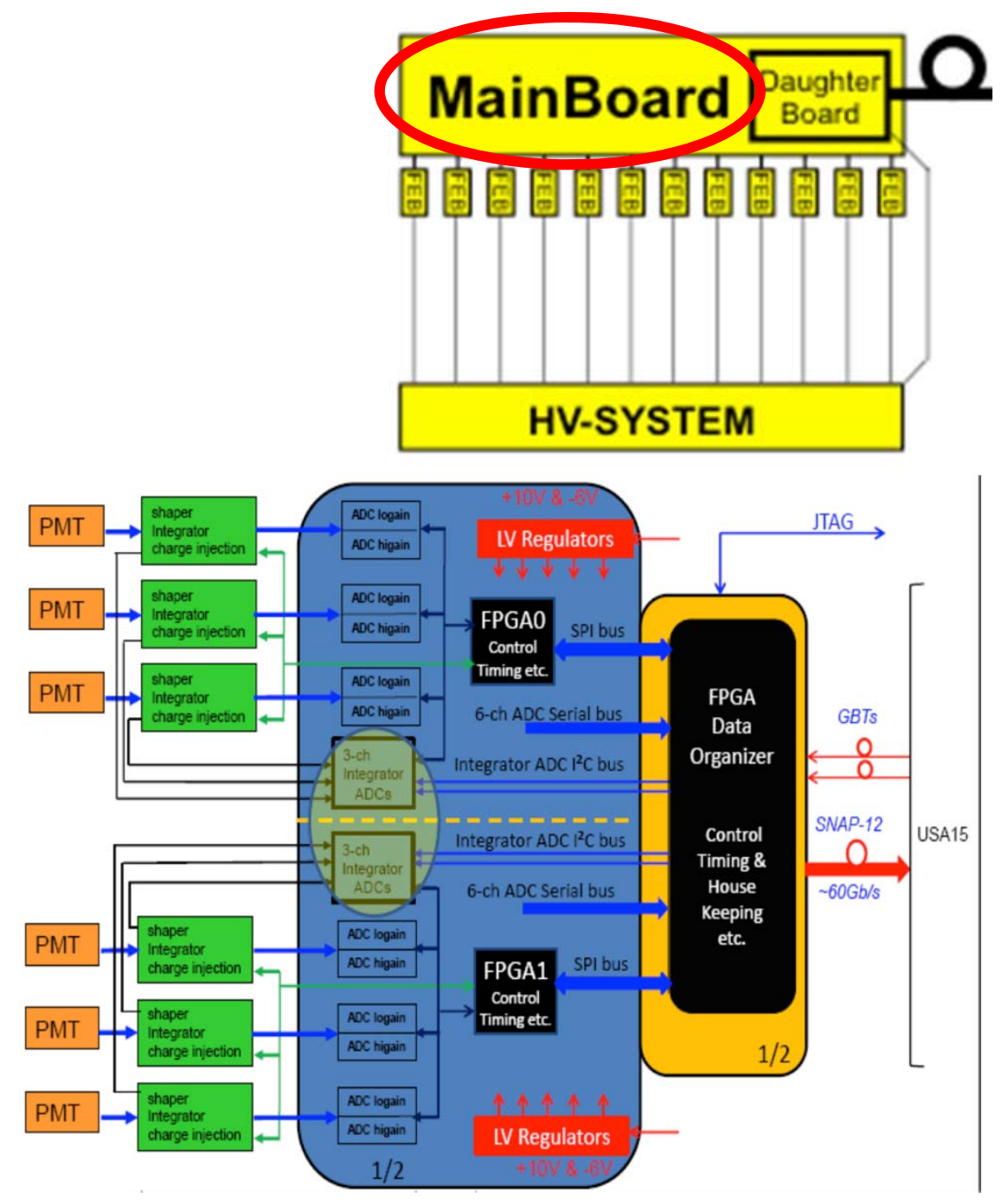

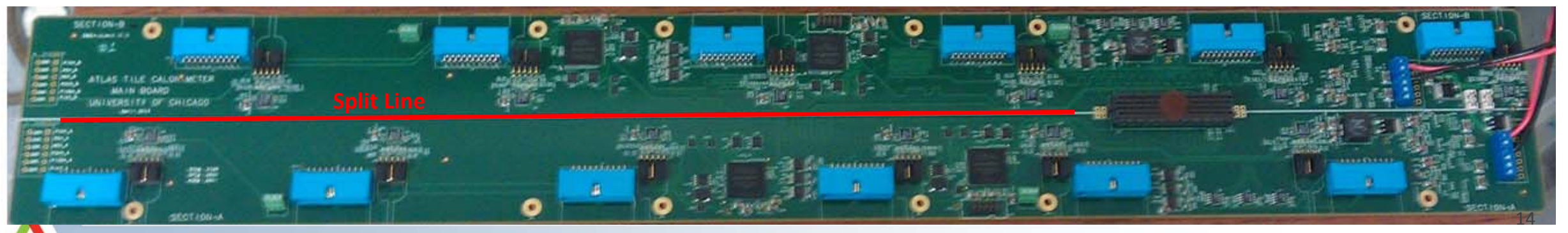




\section{Daughter Board}

- Functionality

- Interface between Main Board and OffDetector Readout

- Receives data streams from front ends and formats for readout @ 9.6 Gbps

- Handles all clock functions

- Interface for slow controls \& calibrations

- Board is split so that 2 halves independent in data \& power for redundancy

- Each half board reads out 6 PMTs

- Baseline design

- Hosts (2) Kintex 7 FPGAs, each of which reads out half of a Main board

$\rightarrow$ FPGA provides serialization

$\rightarrow 2$ devices provide redundancy

- Readout uses GBTx and 10 Gbps QSFP+ Luxtera Modulators

- Contains Point-of-Load (POL) Regulators for regulating $+10 \mathrm{~V}$ to voltages needed by DB circuits

- Will use TMR and scrubbing in FPGA to guard against SEU

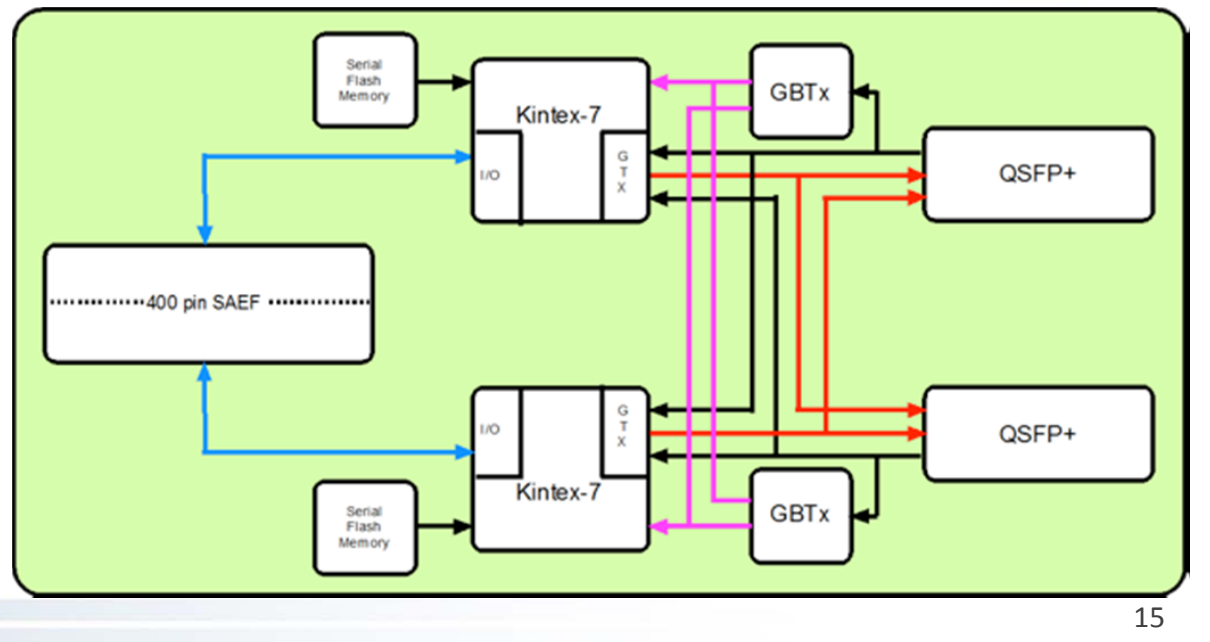


- Functionality

- Each has 4 X 10 Gbps bidirectional optical links

- Mach-Zender modulation technology

- Excellent BER: 10-18 1 error in 100 days!

- Baseline design

- Commercial device: Luxtera Active Optical Link

- Use (2) per daughter Board $\rightarrow 8$ per Drawer

- Require 8 read-out links per demonstrator

- Fab tech: $130 \mathrm{~nm}$ Silicon On Insulator CMOS

- No SEU at TID of $165 \mathrm{kRad}$ and fluence of $8 \mathrm{E} 11 \mathrm{p} / \mathrm{cm} 2$

- PIC microcontroller survives 20 kRad (replacement being developed)

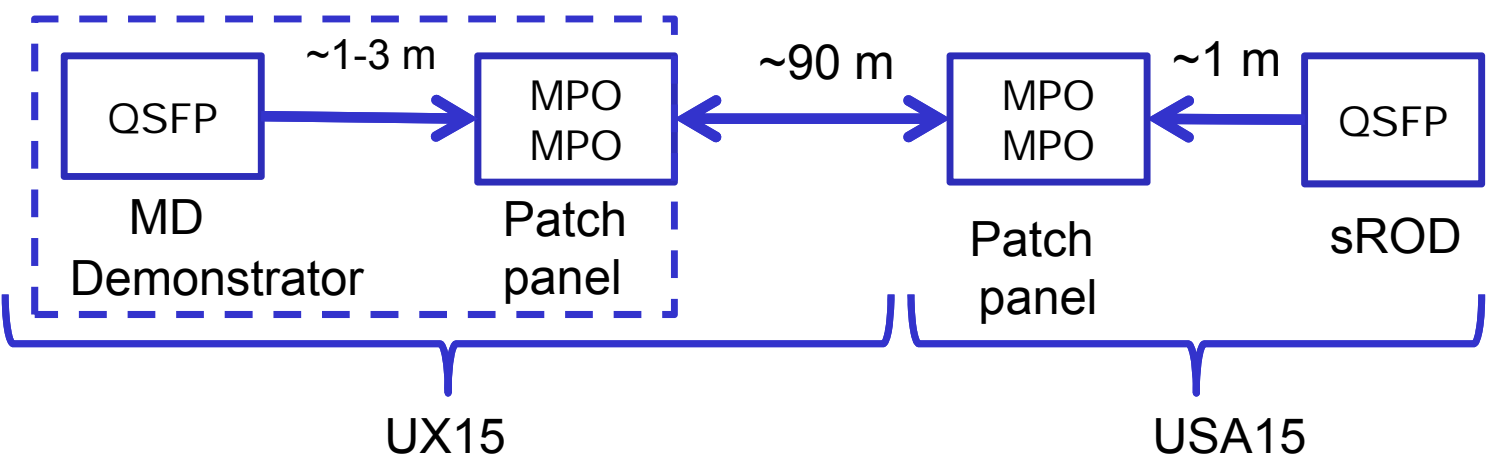

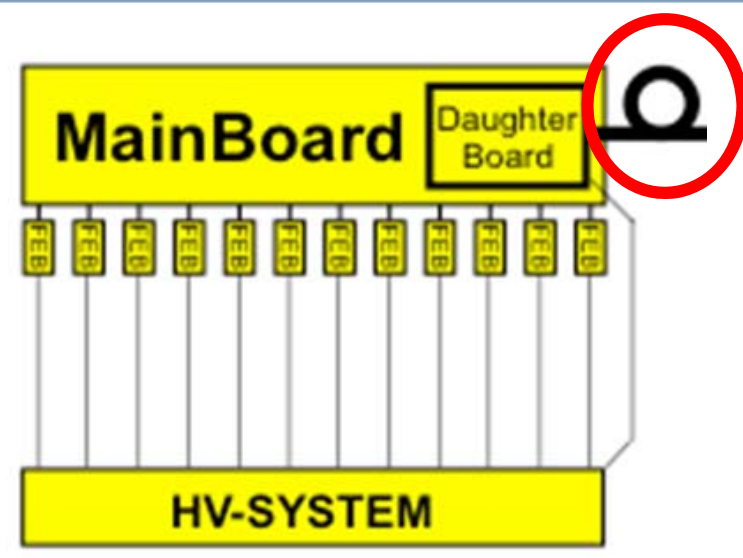

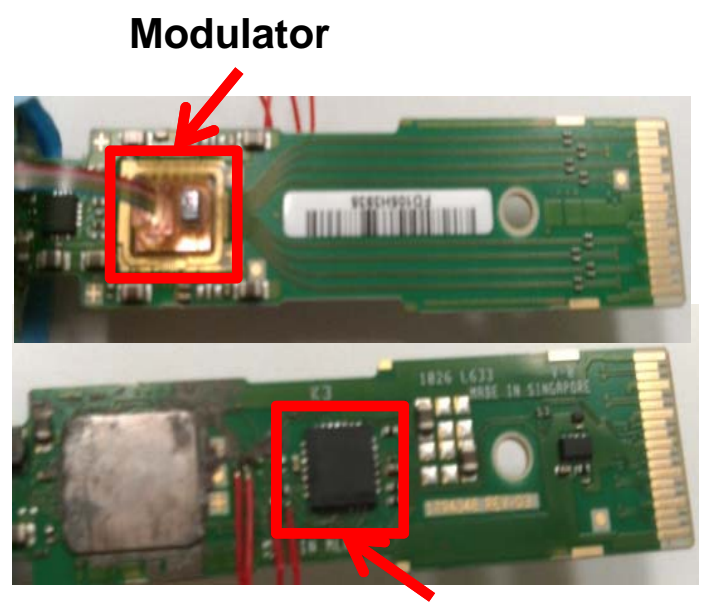

PIC Microcontroller

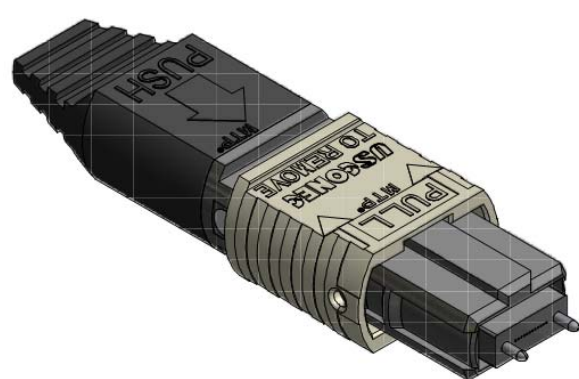

Electronics for ATLAS TileCal Phase 2 Upgrade - G. Drake - 2015 IEEE NSS, San Diego, CA - Nov. 3, 2015 


\section{High Voltage System}

- Functionality

- Bulk 900V provided to Drawer

- Can set HV on individual PMTs

- Include HV read back

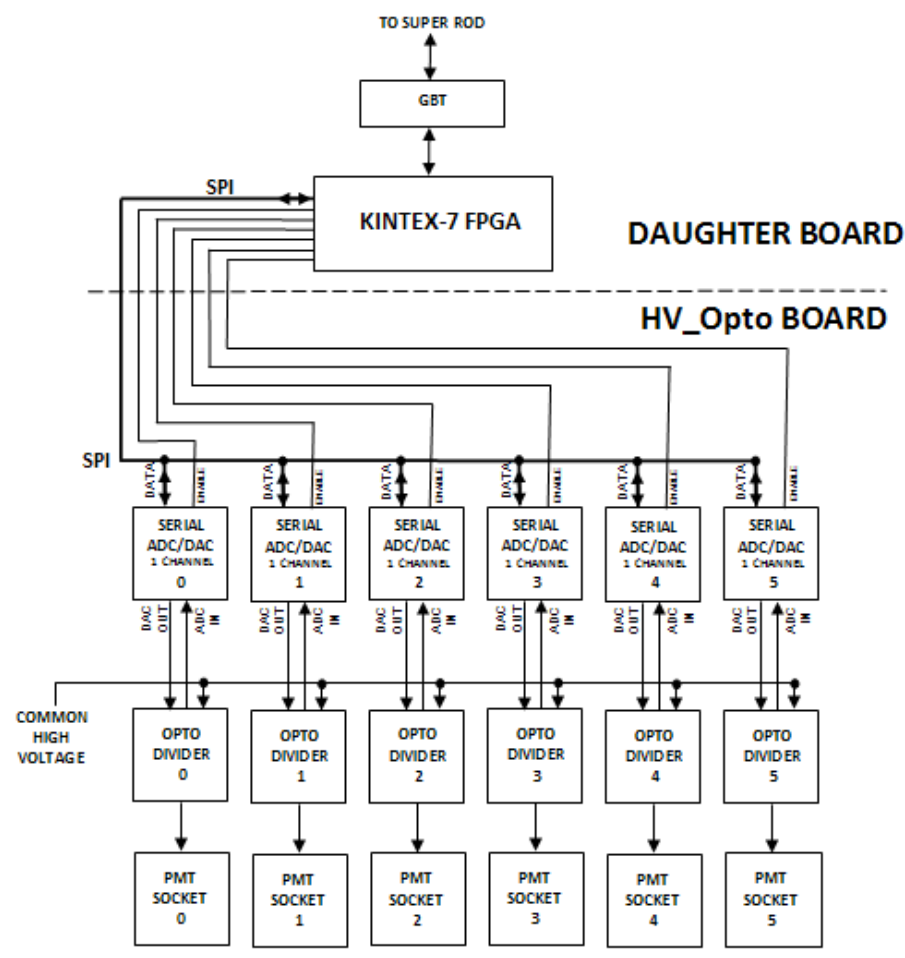

- Board is split, independent power \& data I/O for each half

- Baseline design

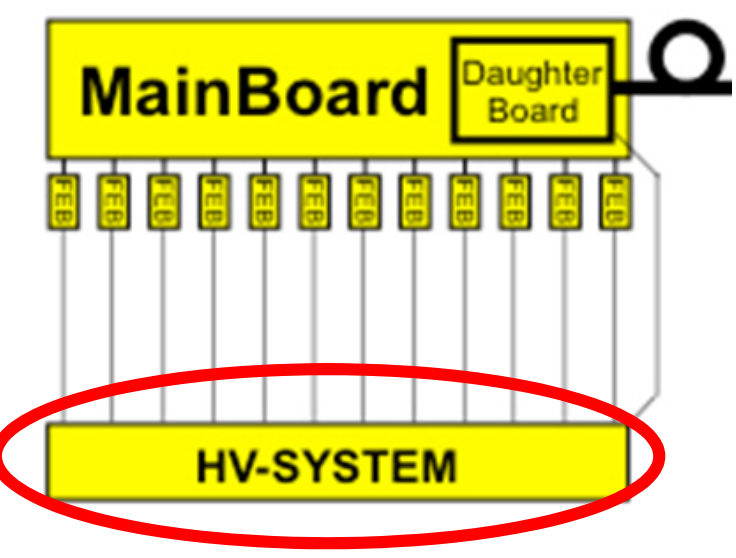

- 12-channel board, 6 channels per side

- Individual control \& monitor circuits for each PMT

- Uses microcontroller per channel

- On-board ADC, DAC, analog circuitry

- SPI Interface

- Data interface with Kintex 7 on Daughter Board

- Contains on-board POL regulators

$\Rightarrow 1$ Alternative Option being Considered: $\Rightarrow$ Remote Control (off detector)

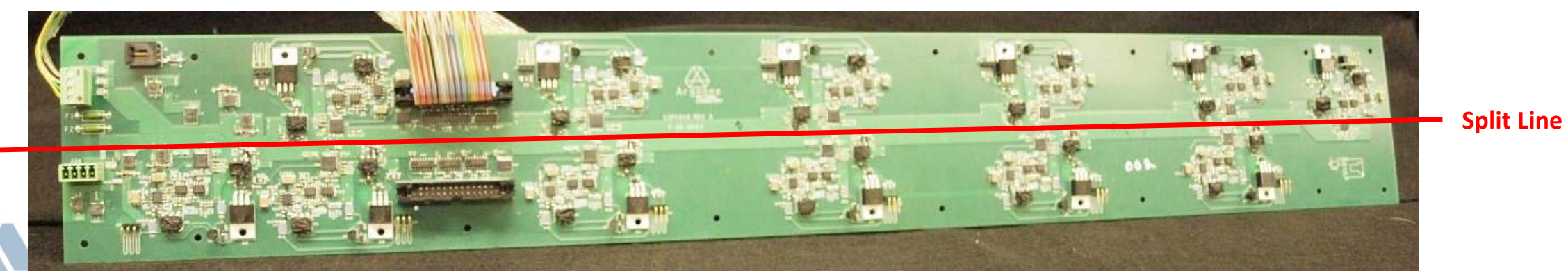




\section{Low Voltage Power Supply}

- 3 stage power distribution system design:

- $\quad$ Stage 1 - bulk 200V in USA15

- Stage 2 - LVPS boxes - 8 bricks per box

- +/- 10V bricks, 7A (14A for redundancy)

- Stage 3-Point-of-Load regulators

- Several commercial \& custom options being considered

- Radiation tolerance is critical aspect

- Redundancy

- Each brick powers half of a Main Board

- Use Diode-OR on Main Board

- When one brick fails, diodes allow second brick to provide power

- Fuses provide protection in case of short on Main Board
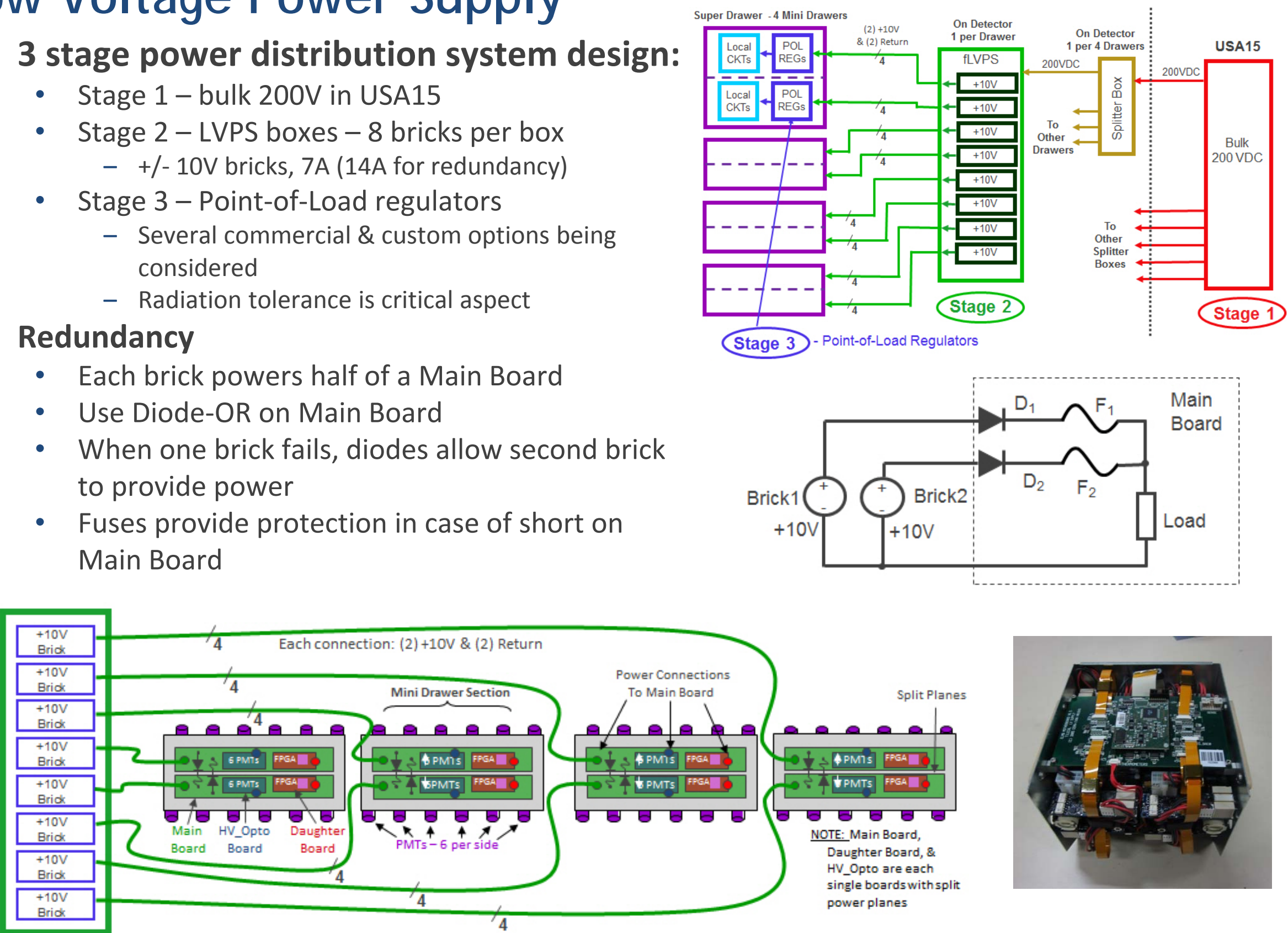


\section{Trigger Preprocessor (PPR)}

- Functionality

- Receives high-speed data from FE

- Provides data to L1/LOCALO

- Saves data in pipelines pending trigger

- Signal reconstruction, L2 algorithms

- Interface with DAQ

- Monitoring, DCS, \& TTC to FE

\section{- Baseline design}

- $\quad$ ATCA module - payload card

- $\quad$ Each card services 8 links (1 Drawer)

- Demonstrator

- Use AMC Demo board

- 1 Xilinx Virtex 7 FPGA

- 1 Xilinx Kintex 7 FPGAs

- 2 GB DDR3 SDRAM

- Compliant with ATCA carrier
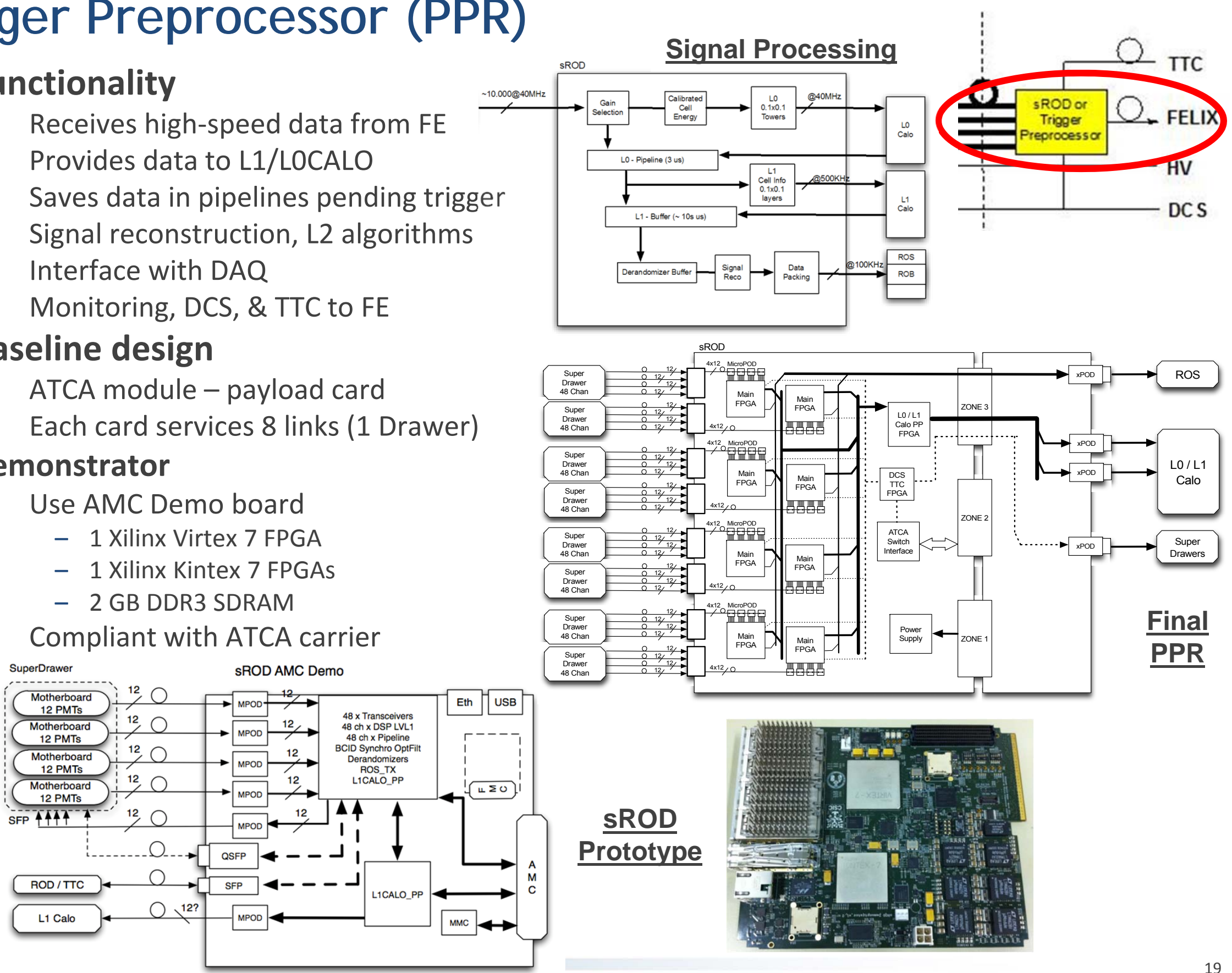


\section{Current Status of Design}

- Mini Drawer mechanics $\Rightarrow$ Design nearly complete; Small production run starting

- Front-End Boards

- 3-in-1 FEB

- FATALIC ASIC FEB

- QIE ASIC FEB

- Main Board

- 3-in-1 MB

- FATALIC ASIC MB

- QIE ASIC MB

- Daughter Board

- Optical Links

- HV Control

- Internal option

- Off-detector option

- LVPS \& POL regulators

- Trigger Preprocessor

- Active PMT bases
$\Rightarrow$ Design complete; Small production run in progress

$\Rightarrow A S I C$ in hand; Prototyping in progress

$\Rightarrow$ ASIC in hand; Prototyping in progress

$\Rightarrow 1^{\text {st }}$ prototype complete; $2^{\text {nd }}$ prototype in progress

$\Rightarrow 1^{\text {st }}$ prototype in progress

$\Rightarrow 1^{\text {st }}$ prototype starting; Will use FATALIC MB

$\Rightarrow 1^{\text {st }}$ prototype complete; $2^{\text {nd }}$ prototype in progress Firmware development in progress; Yet to do: TMR

$\Rightarrow$ Commercial devices being used for $1^{\text {st }}$ prototype

$\Rightarrow 1^{\text {st }}$ prototype complete

$\Rightarrow 1^{\text {st }}$ prototype complete

$\Rightarrow$ Design complete; Small production run in progress

$\Rightarrow$ PPR emulator functional; $1^{\text {st }}$ prototype in hand

$\Rightarrow$ Design complete; Small production run complete

$\Rightarrow$-1 year of development, debugging, \& testing completed

$\Rightarrow$ Completed $1^{\text {st }}$ test beam tests at CERN $\rightarrow$ Data being processed 


\section{A Few Results}

- Channel linearity using pedestal DACs
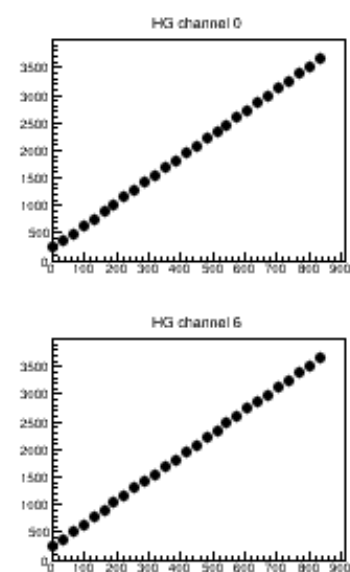

LG Channad 0

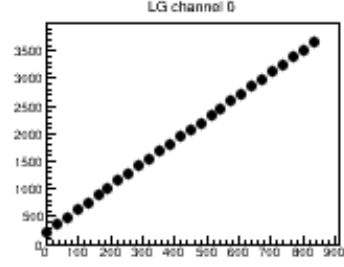

LG channa i 6

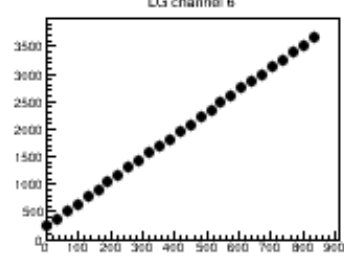

HG channal 1
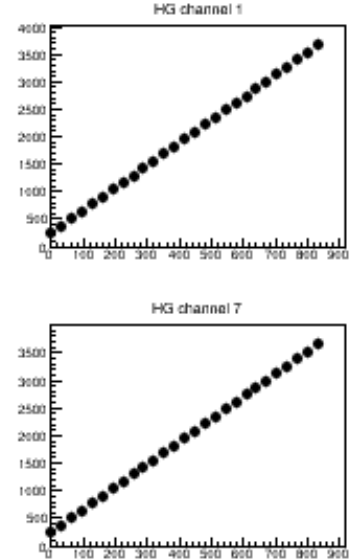

Lạ channa

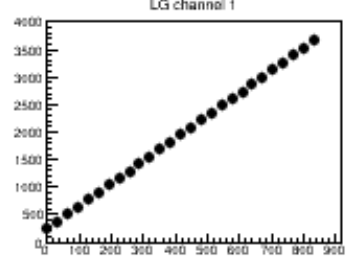

Lü channed

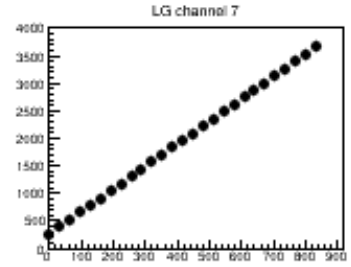

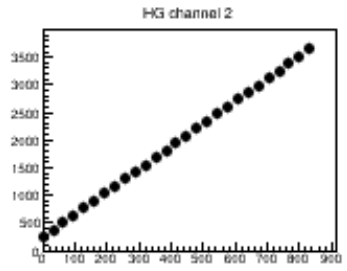

HG channel

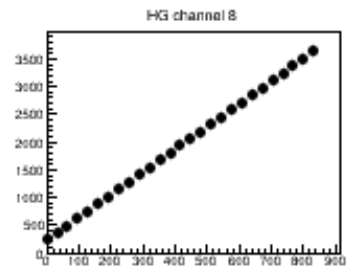

La channat 2

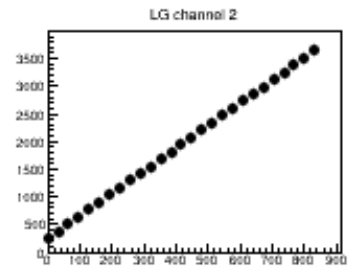

LG channo \&

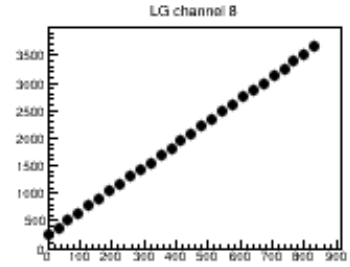

HG channel 3

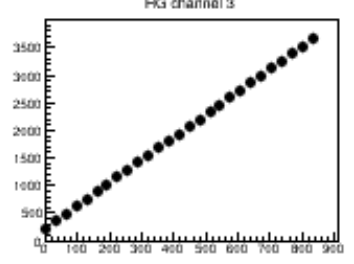

Ha crannals

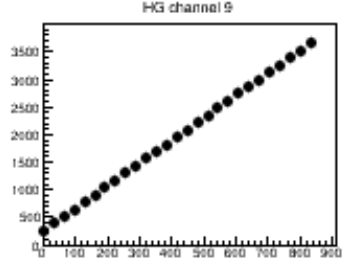

La channe 3

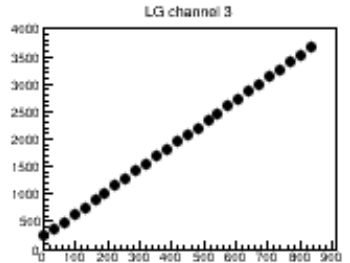

Lä channed?

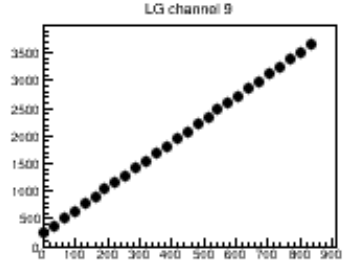

Ha crannal 4

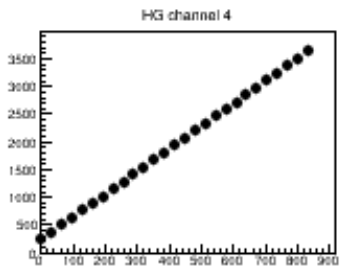

Ha crannal 10

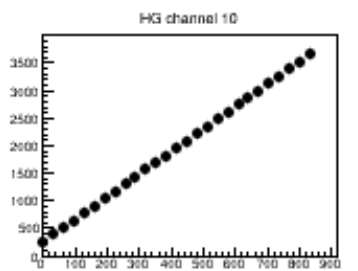

La channel 4

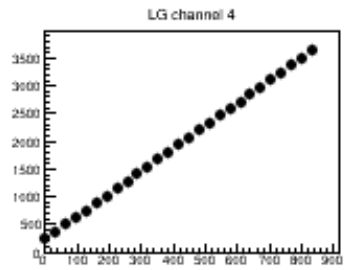

La channel 10

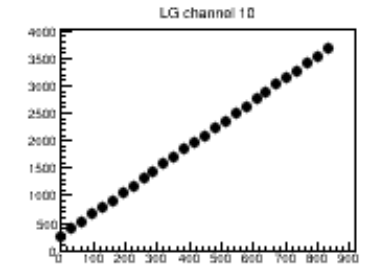

Ha channal 5

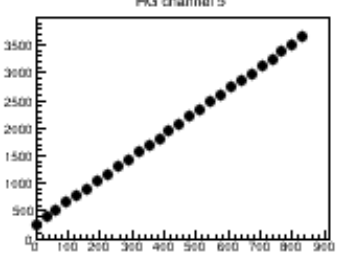

HG ctrannal 11

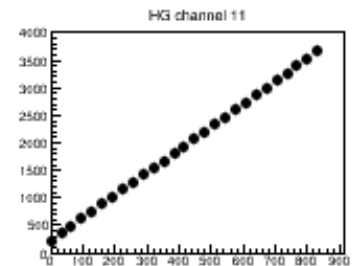

Lachanno 5

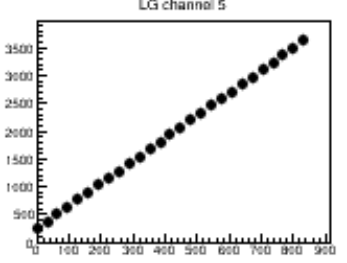

LG channal 11

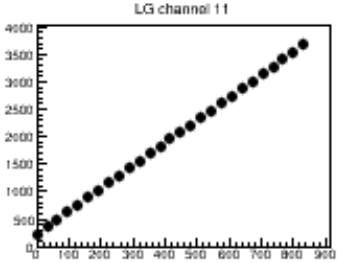

Electronics for ATLAS TileCal Phase 2 Upgrade - G. Drake - 2015 IEEE NSS, San Diego, CA - Nov. 3, 2015 


\section{A Few Results}

- Calibration \& Noise Measurements
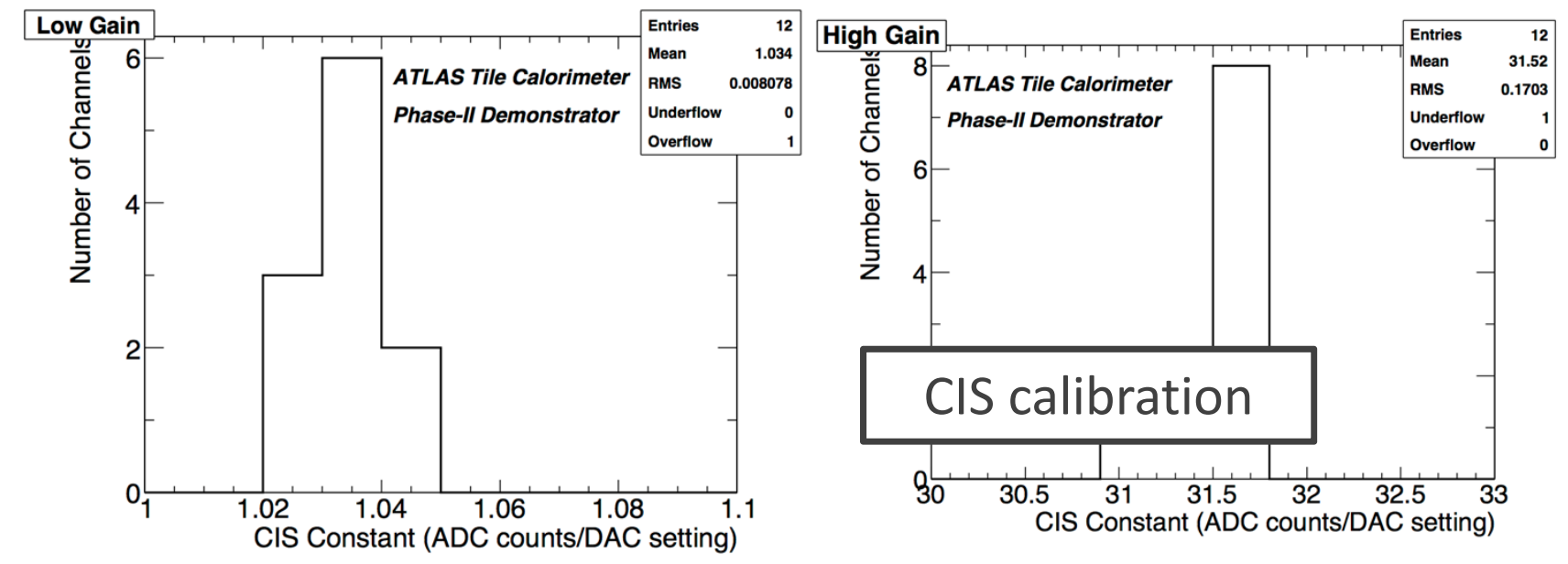

channel 1 gain 1
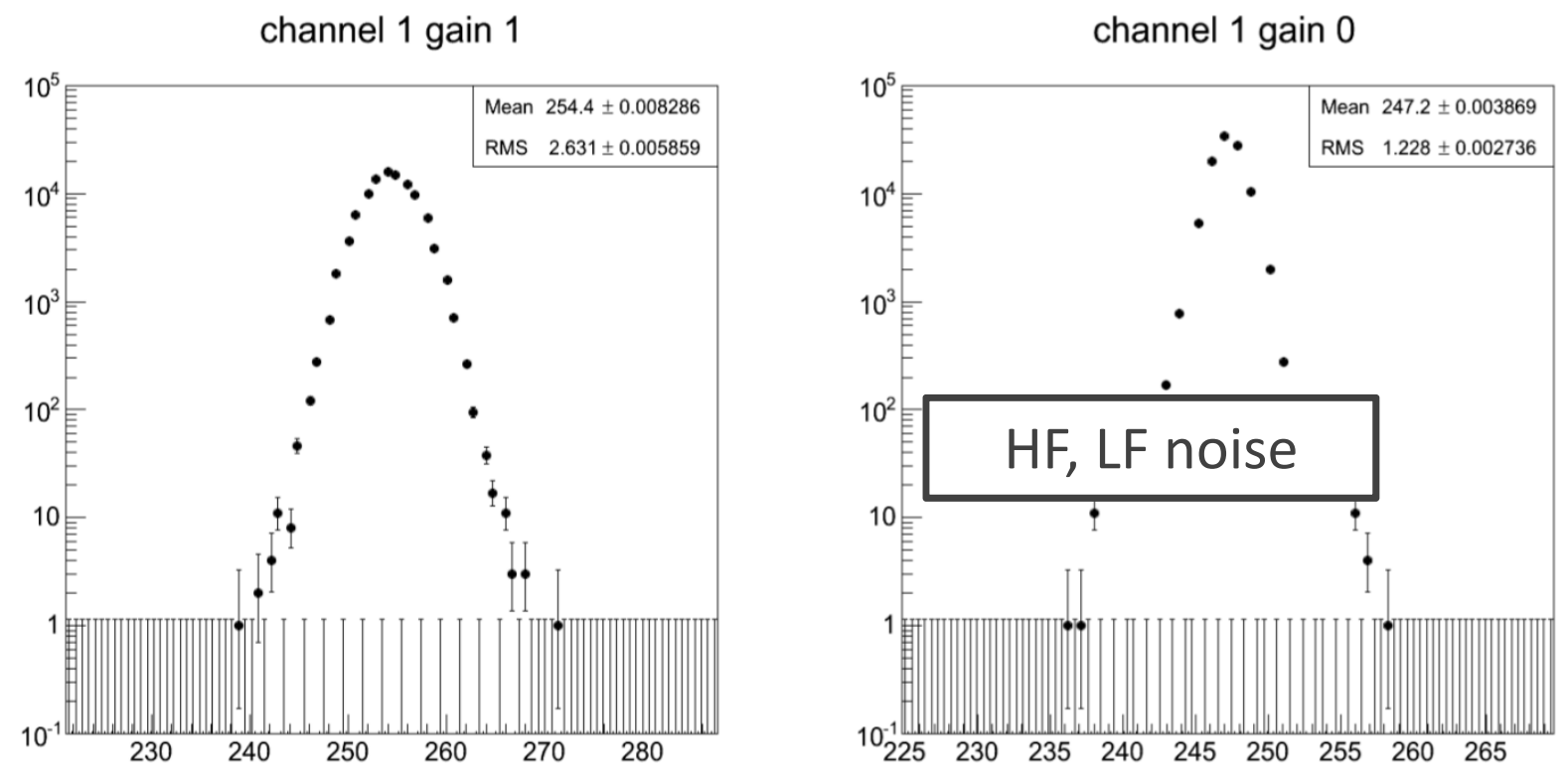

Electronics for ATLAS TileCal Phase 2 Upgrade - G. Drake - 2015 IEEE NSS, San Diego, CA - Nov. 3, 2015 


\section{Status of the Radiation Testing}

\section{- Limits}

- Limits set for each component type by location

- Order of magnitude (10 year operation with safety factors): TID: 25 krad; NIEL: 6E12 p/cm²; SEE 1 E12 p/cm²

\begin{tabular}{|c|c|c|c|c|}
\hline Subsystem & TID & NIEL & SEE & Comments \\
\hline COTS Regulators & $\begin{array}{l}\text { Done - } \\
\text { Mostly OK }\end{array}$ & Not Done & Not Done & $\begin{array}{l}\text { Need different }-5 V \text { Reg } \\
\text { CERN FEASTMN is a candidate }\end{array}$ \\
\hline 3-in-1 & Preliminary & Pending & Preliminary & Preliminary tests done; Full Testing Needed \\
\hline Main Board & Not Done & Pending & Not Done & ADCs tested by BNL; Board size? \\
\hline Daughter Board & Not Done & Pending & Preliminary & $\begin{array}{l}\text { More SEE Testing Needed; TMR not } \\
\text { implemented; Scrubbing needs study }\end{array}$ \\
\hline Modulator & Done-OK & Pending & Done - OK & $\begin{array}{l}\text { No failures, PIC replacement being studied, } \\
\text { Some SEUs in received data }\end{array}$ \\
\hline HV_Opto & Done - OK & Done - OK & Done - OK & No failures, Some anomalies, Mostly OK \\
\hline LVPS & $\begin{array}{l}\text { (Done for } \\
\text { V7.5) }\end{array}$ & $\begin{array}{l}\text { (Done for } \\
\text { V7.5) }\end{array}$ & $\begin{array}{l}\text { (Done for } \\
\text { V7.5) }\end{array}$ & $\begin{array}{l}\text { Mostly same parts as previous design; } \\
\text { Needs Full Testing }\end{array}$ \\
\hline Adders & Not Needed & Not Needed & Not Needed & Same as current; Testing Not Needed \\
\hline Active bases & Done & Done & Not Needed & Good to Go \\
\hline
\end{tabular}




\section{Summary}

- TileCal upgrade goals and specifications are defined

- Development program is in progress

- The project has been divided into upgrade tasks, with groups identified

- Designs and prototypes of each sub-system are progressing well

- Development program has some options and alternatives

- Choices will have to be made... $\rightarrow$ At the time of the TDR (2017)

- A schedule has been defined for development and testing

- Prototypes

- Vertical slice

- Test beam

- Tests on-detector $\rightarrow$ "Demonstrator"

- Radiation tests

$\Rightarrow$ The Demonstrator allows realistic testing of new electronics on the detector

$\Rightarrow$ 1st tests with detector possibly in 2016

$\Rightarrow$ Goal: Basic design complete by 2018; Production to follow

$\Rightarrow$ Most significant yet-to-do: Integration with L1Calo, TDAQ, \& FELIX

\section{The TileCal Phase 2 Upgrade project is well underway!}

